\title{
$\phi$
}

\section{A comunicação digital multiplataforma do Senado Federal}

\author{
The brazillian Senate towards multiplatform \\ digital communication: limits and perspectives
}

Ana Lucia Romero Novelli ${ }^{1}$

Sarah Albertina Cerqueira Nunez ${ }^{2}$

\begin{abstract}
Resumo: O objetivo deste artigo é analisar a expansão do uso de canais e formatos digitais para a distribuição de notícias pelas mídias legislativas do Senado Federal. Obtiveram-se informações por meio de pesquisa documental, observação participante e entrevistas concedidas por profissionais da Secretaria de Comunicação. Desde o surgimento das mídias legislativas de massa (Rádio, TV e Agência Senado), na década de 1990, até os dias atuais, houve um movimento consistente de expansão, com o portal multimídia e a presença digital consolidada em redes sociais. A Secom poderia, contudo, acompanhar o mercado de jornalismo digital de maneira menos reativa, alinhando melhor a expansão à missão institucional de contribuir para o exercício da cidadania.
\end{abstract}

Palavras-Chave: Comunicação pública. Mídias legislativas. Webjornalismo.

\begin{abstract}
This article aims to analyze the expansion of digital channels and formats for delivering news produced by legislative media of Brazillian Senate. Information was obtained through documentary research, participant observation and interviews given by professionals from Secretaria de Comunicação. Since the emergence of mass legislative media in Brazil (Radio, TV and Agência Senado), in the 1990s, to the present day, there has been a consistent movement of expansion, including the establishment of a multimedia portal and the consolidated digital presence on social networks. Secom could, however, follow the digital journalism market in a less reactive way, better aligning this expansion to the institutional mission of contributing to citizenship exercize.
\end{abstract}

Keywords: Public communication. Parliament media. Webjournalism.

\section{Introdução}

O objeto deste artigo é o avanço da Comunicação do Senado Federal em direção à presença digital multiplataforma. O objetivo é analisar o uso de canais e formatos para a distribuição de notícias pela casa legislativa, identificando argumentos

\footnotetext{
${ }^{1}$ Diretora de Relações Públicas e Comunicação Organizacional do Senado Federal; doutora em Ciências da Comunicação pela Escola de Comunicação e Artes da Universidade de São Paulo. Foi Secretária Geral do Conselho Federal de Profissionais de Relações Públicas (2007-2010) e Diretora Científica da Associação Brasileira dos Pesquisadores em Comunicação Organizacional e Relações Públicas (2012-2014), analucianovelli@gmail.com

${ }^{2}$ Analista legislativo da Secretaria Agência Senado; mestre em Poder Legislativo Centro de Formação, Treinamento e Aperfeiçoamento da Câmara dos Deputados, especialista em Gestão Pública pela Escola Nacional de Administração Pública. sarahnunezanalista@gmail.com.
} 
mobilizados pelos profissionais da Secretaria de Comunicação (Secom) sobre o assunto. Até que ponto este processo ocorre para acompanhar práticas identificadas no mercado privado e até que ponto a presença digital multiplataforma é implementada com base em uma estratégia institucional de segmentar e estruturar a produção noticiosa em função de garantir maior transparência e visibilidade ao trabalho legislativo?

Uma nova ecologia dos meios de comunicação, que considera a relação entre as características do meio e sua influência em determinada sociedade, requer a análise de novos comportamentos e preferências da audiência, principalmente no que se refere ao rompimento da barreira da massificação em direção à segmentação dos públicos, no contexto da passagem do ambiente analógico para o digital.

A incorporação do jornalismo digital e das mídias sociais como plataformas de distribuição de conteúdo resulta em novos modelos de comunicação e interação com a audiência. Se anteriormente os veículos de massa se encarregavam de empacotar os produtos de comunicação e distribuir aos consumidores, agora, a lógica dos canais em mão dupla demandam novas posturas dos produtores de informação.

No caso da Secom do Senado, desde a década de 1990, o funcionamento da atividade jornalística se baseou na distribuição de notícias por meio de veículos de massa: Rádio, TV, Jornal e Agência de Notícias. Tratavam-se, essencialmente, de canal broadcasting de TV, emissoras OC, AM e FM de rádio, jornal impresso e sites próprios. Com a criação do portal "Senado Notícias", que reunia as páginas de todos os veículos de comunicação na internet, e o surgimento das plataformas de redes sociais, o Senado passou, especialmente a partir de 2009, a distribuir de forma mais intensa seu conteúdo informativo e noticioso também nos canais digitais.

O movimento de expansão multiplataforma da Secom nos últimos anos deixa clara sua proposta de ocupação de novos espaços de distribuição de conteúdo, mas as justificativas elencadas pelos profissionais da área para tal expansão não são homogêneas: trata-se da (mera) ocupação de espaços, acompanhando tendências de crescimento de público nestas redes? Ou a busca por uma segmentação estratégica, em que a presença digital em cada uma das plataformas implica também mudar a forma de produção de conteúdo visando metas de captação e de engajamento de determinados nichos de público?

Entre 2019 e 2020, Nunez (2020) realizou entrevistas semiestruturadas com 16 jornalistas da Secretaria de Comunicação para investigar a percepção dos 
profissionais sobre a integração dos diversos veículos da Secom, os tipos de convergência que poderiam ocorrer neste processo e as percepções e projeções sobre o cidadão-consumidor de notícias do Senado. Desse conjunto de entrevistas, pode-se identificar alguns fatores indicados pelos profissionais com relação à expansão multiplataforma. Outros fatores puderam ser identificados por análise documental e por observação em campo por parte das autoras deste artigo, ambas pertencentes ao quadro de servidores da Secom do Senado Federal.

No ambiente digital, ao mesmo tempo em que o Jornalismo é colocado em cheque no contexto de múltiplos emissores via mídias sociais (GANDOUR, 2016), a produção de conteúdo de boa qualidade, em novos formatos e para novas plataformas, é ressaltada (ITO, 2019). Nesse contexto, analisar os pressupostos da Secretaria e de seus profissionais para introduzir novas mídias e formatos em seu portfólio de distribuição de conteúdo permite considerar a existência (ou inexistência) de uma estratégia de comunicação integrada, baseada na ocupação de espaços digitais e orientada ao cidadão, em busca de mais eficiência comunicativa.

\section{Lá e cá: o paralelismo da evolução das mídias privadas e do Senado}

A formação do sistema de comunicação do Senado tem forte vinculação com o desenvolvimento das tecnologias de comunicação. Embora contasse, desde os anos 1960, com uma pequena estrutura dedicada à produção de conteúdo noticioso e assessoria de imprensa, foi somente nos anos 1990 que a Secom se consolidou como sistema de comunicação.

A proposta pioneira de dotar uma casa legislativa com seus próprios canais de comunicação demandou grande empenho administrativo e político. Em 1991, o Senado admitiu por meio de concurso público 38 jornalistas com a missão de elaborar o projeto de uma estrutura de comunicação capaz de atender às necessidades de transparência e visibilidade da atividade legislativa. O projeto contemplou todos os veículos de comunicação de massa disponíveis na época e assim, em maio de 1995, foi inaugurado o Jornal do Senado; em fevereiro de 1996, a TV Senado; e, em janeiro de 1997, a Rádio Senado e a Agência Senado.

Particularmente no caso da mídia eletrônica, a grande impulsionadora foi a aprovação da Lei $n^{\circ}$ 8.977/1995 que, ao regulamentar o serviço de TV a cabo no 
Brasil, reservou um canal específico para o Senado Federal documentar seus trabalhos e transmitir ao vivo as sessões plenárias.

Mesmo considerando as suas especificidades em relação ao universo de cobertura, circunscrito ao ambiente legislativo do Senado Federal, os canais de comunicação recém-inaugurados se organizaram a partir da mesma lógica de produção que os canais similares da mídia privada, com pouca integração e alto grau de autonomia. A produção de conteúdo e distribuição nas correspondentes plataformas ocorriam de forma independente observando apenas as necessidades de linguagem de cada veículo específico. O intercâmbio entre os quatro veículos era praticamente inexistente, sendo cada um responsável por sua própria produção, cada um com sua própria redação e jornalistas setorizados.

No entanto, o surgimento e a popularização da internet, ainda no decorrer da década de 1990, marcaram o início da indefinição entre as fronteiras dos vários veículos de comunicação oferecendo a oportunidade de convergência de mídias e linguagens. Com a internet, notícias no formato de texto, áudio, foto e vídeo passaram a habitar a mesma plataforma de distribuição trazendo mudanças e inovações na gestão dos sistemas públicos e privados de comunicação.

Aos poucos, a entrada dos computadores nas redações e as possibilidades de novas linguagens da internet foram alterando o processo produtivo do jornalismo de forma a abranger possibilidades de interação e formatos não disponíveis nos canais tradicionais.

Este novo desenho da produção jornalística, adaptado ao universo digital, pode ser classificado em gerações que indicam momentos evolutivos distintos, a partir do tipo de conteúdo produzido. Segundo Carla Schwingel (2008, p. 64), o jornalismo online ou webjornalismo, passou pelas seguintes etapas:

a) Experiências de primeira geração - a partir de 1992, quando começam a aparecer informações noticiosas em páginas web. Os produtos são praticamente transpostos de forma integral do impresso para a web.

b) Experiências de segunda geração - a partir de 1995, quando os produtos começam a apresentar características específicas da web, como a personalização e a interatividade. Apesar de começarem a se diferenciar, os produtos permanecem vinculados ao modelo metafórico do veículo impresso.

c) Experiências de terceira geração - a partir de 1999, quando os produtos são elaborados tendo em vista os diferenciais do ciberespaço, já sem uma vinculação direta com o modelo de um produto somente impresso. Começam a integrar também o radiojornalismo e a televisão; o audiovisual ganha força, bem como os mecanismos de interatividade. O processo de produção da informação é totalmente controlado pelos jornalistas. Sistemas de gestão de 
conteúdos começam a ser utilizados na elaboração dos produtos jornalísticos, com a utilização de banco de dados integrados ao produto.

d) Experiências de quarta geração - a partir de 2002, com o uso de banco de dados integrados das empresas de comunicação, com o uso de sistemas de produção de conteúdos, com a incorporação do usuário no processo de produção, ou seja, com mecanismos do jornalismo colaborativo (SCHWINGEL, 2008, p. 64).

Suzana Barbosa (2013) complementa esta perspectiva afirmando que as características de produção e consumo da informação para os dispositivos móveis, como celulares e tablets, já podem se configurar como a quinta geração do jornalismo digital.

Como agentes de inovação, renovação e de reconfiguração para o jornalismo no atual contexto da convergência jornalística, as mídias móveis possuem gramática própria, práticas de produção, dinâmicas de consumo e modelos de negócio específicos (BARBOSA, 2013, p. 43).

Considerando que as organizações se encontram em distintos níveis de evolução tecnológica, um mesmo sistema jornalístico pode ocupar estágios geracionais distintos de forma simultânea. Desta forma, mesmo que a linguagem de um veículo não esteja totalmente adaptada para o ambiente digital, é possível que o veículo de comunicação já utilize formatos e estratégias de quarta ou quinta geração em sua produção de conteúdo.

Com os veículos de comunicação do Senado Federal, esta tendência não é diferente, sendo possível afirmar que uma das grandes iniciativas de ocupação de espaço midiático ocorreu quando os canais de massa tradicionais passaram a ocupar também o espaço de distribuição e visibilidade da internet por meio do portal do Senado. Neste momento, por exemplo, a TV Senado deixou de veicular seus conteúdos exclusivamente por meio do aparelho de televisão e passou também a distribuir seus produtos por site próprio e, em 2010, também por um canal exclusivo no YouTube.

Um dos impactos da chegada da internet para o jornalismo profissional é a mudança na forma como o público consome notícia. No ambiente digital, qualquer pessoa pode tornar-se um potencial publicador de informação. Esta característica fez com que muito da produção jornalística precisasse buscar formatos mais significativos e relevantes para manter sua audiência. 
Contudo, até 2009, cada veículo de comunicação do Senado atuava na internet com a mesma independência observada no canal broadcast, administrando e gerindo a produção dos conteúdos tanto para o veículo original quanto para a respectiva página na internet, mais próximo do que foi descrito como jornalismo de segunda geração.

Após este período, a Secom definiu sua primeira estratégia de integração dos canais de distribuição online e criou um site agregador, o Senado Notícias. A proposta deste novo espaço no portal do Senado era reunir todas as notícias no mesmo local independentemente de seu formato, seja texto, áudio, vídeo ou foto.

A partir da página do Senado Notícias, o usuário seria direcionado às páginas próprias dos veículos de comunicação, cujo diferencial era a disponibilização no formato digital dos mesmos conteúdos disponíveis nos respectivos canais broadcast.

Nesta fase, a integração ocorreu muito mais pelo compartilhamento do espaço de distribuição do que por uma real adequação de linguagem e formatos para o ambiente web. É deste período também a incorporação das redes sociais ao sistema de comunicação do Senado.

Foi somente em 2013 que a Secom definiu que os conteúdos seriam produzidos de forma colaborativa entre todos os veículos e criou a Central de Pautas, posteriormente denominada Diretoria de Jornalismo. Com esta nova diretoria, a pauta da produção noticiosa passou a ser integrada e compartilhada entre os veículos com maior aproveitamento e otimização dos recursos, incluindo a utilização de ambiente de produção virtual e colaborativo. Embora cada veículo mantenha sua própria redação com seu grupo de jornalistas especialistas na linguagem de cada veículo, a troca de informações se tornou essencial para garantir a qualidade e a universalização da cobertura.

Já em 2015, o Núcleo de Mídias Sociais foi criado com o objetivo de unificar os vários perfis em redes sociais de diferentes áreas do Senado. Nesta fase, a definição pela manutenção de um único perfil institucional de caráter oficial em detrimento da pulverização de oferta de vários perfis segmentados se mostrou bastante eficiente, uma vez que os perfis do Senado Federal estão entre os mais bem colocados entre todos os perfis do segmento de governo. Seja na linguagem ou no conteúdo das publicações nas redes sociais, os perfis do Senado se mostram alinhados às expectativas dos usuários resultando em altos níveis de engajamento dos seguidores. 
Contudo, a estratégia adotada para os perfis dos veículos de comunicação da Secom em relação a presença nas redes sociais foi revisada a partir de dois anos depois com o lançamento de perfis específicos para a TV, a Rádio e a Agência Senado, em complemento ao perfil institucional do Senado Federal. A decisão foi tomada considerando a necessidade de divulgação dos produtos específicos de cada veículo nesse espaço online de visibilidade.

Recentemente, as páginas dos veículos de comunicação passaram por reformulação geral para melhor adaptação ao estilo visual e de conteúdo do ambiente digital. Em 2019, o Jornal do Senado deixou de ser publicado, tanto na versão impressa quanto na versão digital. Desde então, o canal dedicado ao jornalismo escrito é a Agência Senado. O contingente profissional do antigo Jornal do Senado foi absorvido em grande parte pela Diretoria de Jornalismo, dedicando-se ao trabalho de produção de pautas.

As últimas tecnologias incorporadas ao sistema de comunicação do Senado dizem respeito as inovações decorrentes da quinta geração do jornalismo digital, que são o sistema de notificação das atualizações do portal Senado Notícias e a disponibilização de aplicativo, para celular e tablet, dedicado ao conteúdo noticioso legislativo. O aplicativo foi lançado em 2021 no âmbito de adequações promovidas pela Agência, após o encerramento das atividades do Jornal do Senado.

Atualmente, o sistema de comunicação do Senado tem larga presença nos canais broadcast de TV e Rádio com emissoras e repetidoras em todos os estados nacionais, e também forte presença digital, seja no próprio portal do Senado na internet, com páginas próprias para cada veículo, seja nas diversas plataformas de redes sociais, plataforma de troca de mensagens, como Whatsapp e Telegram, e aplicativo para dispositivos móveis.

Se por um lado o sistema de comunicação do Senado parece em contínuo movimento de expansão, por outro, tal como ocorreu com os sistemas privados de mídia, a rápida evolução tecnológica imposta à atividade jornalística tem conduzido os veículos de comunicação, inclusive em suas versões online, a uma constante exigência de reestruturação de processos produtivos, sob pena de defasagem e afastamento do seu público e audiência. 


\section{Expansão multiplataforma: algumas percepções dos profissionais da Secom}

A internet e as redes sociais mudaram a forma pela qual a informação é produzida, consumida e transmitida. Presente em trabalhos de diversos autores (GREIFENEDER et al, 2021; JENKINS, 2009), a ideia é amplamente aceita e até mesmo óbvia.

Contudo, é preciso voltar a esta premissa, para embasar a ideia de que, conforme as plataformas de mídias sociais vão sendo lançadas e ganhando aceitação do público, organizações públicas e privadas, produtoras de conteúdo jornalístico passam a querer garantir presença nesses novos meios, provavelmente alterando e adaptando seus processos produtivos, com maior ou menor intensidade, conforme a plataforma. Isso pode implicar que as organizações se atenham ao formato/lugar de distribuição de notícias, em detrimento de alinhar sua produção à missão e a objetivos estratégicos institucionais.

Seja para garantir presença em redes sociais, seja para acompanhar tendências lançadas por outros "operadores" da notícia, como a de distribuir conteúdo multimídia em sites, alguns produtores passam a lançar novos formatos menos com base no conhecimento sobre a necessidade e o interesse seu público, e mais com base em modelos de negócio "vitoriosos" para outras empresas ou organizações.

No caso da estrutura do sistema de comunicação do Senado, não se trata da crítica à observação das práticas do mercado, à presença das mídias legislativas nas redes sociais, ou aos resultados quantitativos alcançados nessas plataformas, mas de analisar se e até que ponto a presença digital multiplataforma (ainda que acompanhe tendências) é implementada com base em uma estratégia institucional de integrar a pauta dos diversos setores que produzem conteúdo na Secom e de segmentar a produção em função de "contribuir para o exercício pleno da cidadania", conforme é descrita na missão da Secretaria (BRASIL, 2010, p. 9).

A falta de uma estratégia integrada da Secom na definição da pauta e na distribuição de notícias e a necessidade de simplificar a linguagem, o que incluiria produzir novos formatos de notícias, foram alguns dos fatores enumerados pelos profissionais da Secretaria, em entrevista à Nunez (2020), relacionados à expansão multiplataforma. 
Os profissionais veem a necessidade de um melhor uso das diversas plataformas de distribuição, principalmente com relação aos perfis dos próprios veículos de comunicação nas redes sociais, considerando que alguns desses perfis são para públicos mais gerais e outros para públicos mais específicos.

Uma jornalista dá como exemplo a distribuição do programa de entrevistas Argumento, da TV Senado. Segundo a profissional, o produto deveria ser distribuído primeiro para mídias sociais.

Ele é um produto que vai para a TV [grade de programação da TV Senado] frio, que o cara fala na terça e vai ao ar sábado. Imagina o potencial de ele ir ao vivo no Twitter do Senado, com uma audiência mais qualificada, que você conseguisse debater, que as pessoas conseguissem interagir [...]. É para onde as coisas estão caminhando, é a coisa de você não perder o bonde (em depoimento à Nunez, 2020).

O uso do YouTube pela TV Senado é considerado pertinente por outra jornalista da Secom, segundo a qual a casa legislativa "não teria grana para investir num player próprio". Embora esteja em linha com a ideia de que o YouTube é um redutor de custos para o consumo da informação política (MARICHAL, 2012), a profissional da Secom faz ressalvas ao modo de uso do canal pelo Senado.

\begin{abstract}
Nos permitiu ter hoje uma presença digital com multiprogramação. Por outro lado, o YouTube é um canal e a gente tá tratando como um lugar de arquivo da produção da TV. Se eu tivesse o YouTube como canal, eu jamais publicaria nele tudo que a TV faz. Teria produtos específicos. A gente teria muito mais possibilidade de se sobressair com o YouTube se a gente pensasse no YouTube como um canal, que não fosse só repositório. A gente tem perdido um pouco em relação às redes sociais também porque existe um pensamento na TV de que as redes são para divulgar os produtos da TV. E as redes não são para isso. As redes são canais (em depoimento à Nunez, 2020).
\end{abstract}

Alguns dos entrevistados afirmam que estratégias de distribuição, independentemente de plataforma, deveriam ser definidas considerando-se uma preferência do "cidadão comum" (alegada pelos próprios entrevistados) por notícias no formato de vídeo com curta duração/extensão. "Hoje no mundo tem muita informação, então a gente achar que a pessoa vai parar e ler um texto gigante é muita pretensão", disse uma jornalista (depoimento à Nunez, 2020). A percepção de outra profissional da Secom é a de que os textos longos só atraem públicos mais específicos, como jornalistas e consultores. 
Rádio e TV tem uma linguagem mais oral. Se tivesse mais vídeo e mais áudio no portal [Senado Notícias], teria mais cidadão acessando e seria para o cidadão mais informativo e compreensível. Se o portal fosse mais multimídia, talvez ele não abandonasse esses públicos específicos - porque esses públicos seriam atraídos pelo texto - mas também atrairia o cidadão comum [...] o objetivo do Senado é atingir cada vez mais públicos, e não ficar no público específico (em depoimento à Nunez, 2020).

Mesmo que apontem para uma preferência mais geral do cidadão por consumir conteúdo audiovisual, os servidores entendem que há subformatos ou "empacotamentos" mais propícios, dependendo da plataforma de distribuição. Uma servidora entrevistada defende um formato específico para o Whatsapp:

Agora o Senado tem Whatsapp. É uma super rede. É a rede que mais chega em todos os brasileiros, então imagina se ali você entrega a notícia assim num formato que o cara vai gostar de ver? Um videozinho pelo Whatsapp viralizando tem um valor imenso, muito mais do que um jornal que a gente coloca no ar $21 \mathrm{~h} . .$. (em depoimento à Nunez, 2020).

A afirmação da entrevistada está em consonância com o relatório do CETIC (2019), segundo o qual atividades de comunicação foram as mais realizadas na internet, sendo o envio de mensagens instantâneas realizado por $92 \%$ dos usuários, seguido pelo uso de redes sociais $(76 \%)$.

Pode-se falar, de acordo com os jornalistas entrevistados, em uma combinação de plataformas, formatos (vídeo/áudio/texto/multimídia) e empacotamentos (curto, longo, linguagem simples, linguagem aprofundada) como meio para atingir determinados segmentos de público.

Eu não sei se é o caso de o portal [Senado Notícias] desprezar esse público especializado, porque já é um público cativo, que suporta a comunicação que é feita no Senado [...]. Quem cumpre um papel muito complementar nisso são as mídias sociais do Senado. O Senado adotou [nas mídias sociais] uma linguagem absolutamente simples, o foco no cidadão e isso trabalha de forma bem complementar ao que o portal faz. Enquanto o portal está fazendo uma informação para públicos especiais, as redes sociais estão fazendo o bê-abá. Você percebe isso na hora que você olha as métricas na mídia social. $\mathrm{A}$ mídia social normalmente coloca o link para matéria, [...] e os números de acessos são pequenos. O engajamento na mídia social é enorme, às vezes um post tem 12 mil curtidas [...] o grosso da população só quer aquela informação superficial (em depoimento à Nunez, 2020).

Pode-se questionar se, por mídias sociais, as mídias legislativas do Senado cumpririam o objetivo de informar, e se esse de fato é o objetivo da Casa ao garantir 
presença das redes. Nesse ambiente, para Gandour (2016), como a notícia é mercadoria abundante, acaba valendo pouco; o valor dos emissores de conteúdo nas redes seria obter engajamento. O autor ressalta, entretanto, que o jornalismo nas mídias sociais por ser usado como um formato apenas, porque a aparência jornalística dá credibilidade a uma informação, então o conceito de notícia antes citado não é necessariamente associável a jornalismo.

Se por um lado foi avaliado em depoimento anterior que a informação distribuída pelo Senado nas redes sociais é superficial, há, entre os jornalistas entrevistados, principalmente os vinculados à Rádio e à TV Senado, uma percepção de que o conteúdo jornalístico produzido pelos veículos da Secom ainda é muito técnico e formal. Esta produtora afirma:

\begin{abstract}
Ainda acho que a gente é muito técnico...para gente ainda importa mais a comissão que aprovou o projeto do que o que de fato o projeto faz. E pra pessoa lá fora isso pouco importa. O que a pessoa quer saber é o que vai mudar na vida dela. Só que eu acho que a gente nem sempre informa isso. É muito mais fácil você se identificar com uma história do que com um dado. [...] A nossa comunicação ainda é técnica, é muito pra nós, é muito regimental (em depoimento à Nunez, 2020).
\end{abstract}

Outra jornalista também "sente falta" de a Comunicação fazer um conteúdo menos burocrático. "Tentar olhar a informação do ponto de vista de quem consome". Segundo ela, o número do projeto não deve ser o lead. "A gente tem que tentar traduzir isso melhor pro cidadão. [...] A minha impressão é que faz muito sentido para quem está do lado de cá, mas pouco sentido para quem está do lado de lá" (em depoimento à Nunez, 2020).

Embora inexistam pesquisas qualitativas mais extensas sobre o interesse do público que consome informação das mídias legislativas do Senado e que embasem possíveis estratégias com base em segmentação, observa-se, pelas entrevistas realizadas em 2019 e 2020, que boa parte dos gestores têm o hábito de acompanhar o retorno quantitativo de seu conteúdo disponível na internet, e de monitorar interações "qualitativas" do público, ainda que de forma assistemática.

A Rádio Senado recebe mensagens via Whatsapp, recebe via Messenger no nosso perfil, a gente recebe e-mail com sugestões. A Rádio Agência faz alguma promoção e as rádios pedem conteúdos. São alguns retornos que a gente tem e que, apesar de não terem um caráter científico nem quantitativo, 
eles permitem a gente conhecer esse público que demonstra tanto interesse que chega a escrever pra gente (em depoimento à Nunez, 2020).

Os profissionais estão de acordo com a necessidade de haver um planejamento nesse sentido. O último planejamento estratégico da Secom foi publicado em 2010 e ficou vigente até 2018 (BRASIL, 2010). Uma jornalista da Secretaria aponta que uma das questões estratégicas é ter uma linguagem adequada aos públicos que se deseja alcançar:

Quando você faz comunicação, você tem que fazer essa escolha de público. Quando você faz essa escolha por uma linguagem absolutamente simples, didática, você tá fazendo a escolha pelo cidadão, mas tá abrindo mão do público especializado, porque quando a coisa é muito 'be-a-bá', o 'especializado' não quer ver, ele quer algo mais aprofundado que vai explicar o que ele está precisando saber. É uma escolha. Eu concordo com o fato de o portal atender a públicos específicos. A nossa vocação é mais essa. Mas hoje como tem a mídia social, acabou ficando complementar. Acabou dando certo. Se não era estratégia, virou (em depoimento à Nunez, 2020).

Em relação especificamente ao que é produzido pelos veículos - TV, Rádio e Agência Senado - convergido e distribuído pelo portal Senado Notícias, uma gestora da Secom aponta para a necessidade de um planejamento estratégico.

Como a gente vai estrategicamente conseguir melhores resultados? Para quem a gente está oferecendo esse portal? É para todo mundo? O que a gente tá oferecendo? De que forma? Acho que a gente precisa pensar mais estrategicamente e não simplesmente ir colocando conteúdo, tipo 'vamos fazer um conteúdo diferente que eu vi lá no New York Times' (em depoimento à Nunez, 2020).

Sobre convergência de mídias, nem mesmo no mercado privado esse jornalista da Secom vê um modelo de negócio pronto, nem na distribuição nem na produção:

As empresas ainda não têm um modelo de negócios ponto que resolve toda essa convergência [...]. O jornalista em muitos momentos você vê transitando entre o impresso e o vídeo e também o rádio [...], o que exige muito mais do profissional, porque ele tem que dominar linguagens diferentes, ainda que seja formato jornalístico, mas são linguagens distintas. Mas, insisto, não tem uma solução pronta, tá todo mundo tateando. Tem a ver com modelo de negócio, como você ganhar dinheiro produzindo conteúdo jornalístico, já que os jornais estão diminuindo, a tiragem...vários deixaram de existir [...] como levar esse conteúdo para a internet? (em depoimento à Nunez, 2020). 
Considerando o conjunto de entrevistas, vê-se que os jornalistas da Secom acompanham estatísticas de consumo de informação das mídias legislativas na internet; e estão atentos a informações sobre preferência do público por determinados formatos e ao modo mais indicado de usar cada plataforma de distribuição, ainda que, na prática, a adequação do processo produtivo ao modelo de comunicação multiplataforma ainda esteja em construção.

Os jornalistas manifestam ainda, em consonância com o argumento de Ito (2019), que são variados os contextos de consumo bem como os perfis de leitor. Mas, quando se fala em segmentar a distribuição e a produção, o que ainda parece faltar é um alinhamento de metodologias e objetivos estratégicos com a missão da Secom.

"Alcançar o maior número possível de cidadãos, com investimentos em tecnologia e expansão do Sistema de Comunicação do Senado" (BRASIL, 2010, p. 14), é um objetivo estratégico do planejamento vigente até 2018. A questão ainda é avaliar se a presença nas mídias sociais, a distribuição de conteúdo multimídia, e a forma como os veículos e setores se organizam contribuem da melhor forma para o exercício pleno da cidadania.

\section{Considerações finais}

O objetivo deste artigo foi identificar e debater aspectos relacionados à expansão multiplataforma da Comunicação do Senado, coletando informações por meio de observação participante, análise documental e entrevistas.

Até que ponto o movimento de ampliação da presença digital tem ocorrido para acompanhar práticas observadas no mercado privado e até que ponto tem sido implementado com base em uma estratégia institucional de segmentar e estruturar a produção noticiosa em função de dar transparência e visibilidade ao trabalho legislativo, contribuindo para o exercício da cidadania?

É uma questão complexa, considerando que, independentemente de missão e estratégias institucionais, novos formatos criam novas demandas de consumo. Como no mercado privado a inovação costuma ocorrer de forma mais expressiva e perceptível, é natural que as organizações públicas acompanhem tendências.

Nesse contexto, entre os pontos que merecem destaque está o movimento consistente de expansão da Secom, com presença digital consolidada em diversas 
redes sociais e com resultados expressivos em número de seguidores e em outras métricas de engajamento. Iniciada em 2011, a conta do Senado no Instagram tem 1,78 milhão de seguidores, e chegou em 2021 a 5 mil posts publicados. A estimativa é que no Twitter já tenham sido postados, desde 2009, mais de 82 mil tweets; e que na página do Senado no Facebook, tenham sido mais de 10 mil posts desde 2010 (BRASIL, 2021).

Outro ponto de destaque, por exemplo, é a utilização do formato de infomatéria (tipo de matéria jornalística que adota recursos de texto, áudio, vídeo, foto e infografia) pela Agência Senado. Trata-se de formato em que o multimídia é "pensado" desde a concepção da pauta.

Por outro lado, observa-se que o crescimento do número de plataformas e formatos em que o Senado distribui notícias não vem acompanhado de uma reorganização produtiva da Secom, o que muitos jornalistas da área associam a uma cultura organizacional construída em torno da ideia de veículos autônomos. Enquanto a mídia privada se utilizou da reestruturação de redações, da fusão e do rearranjo produtivo, as mídias do Senado preservaram suas estruturas com bastante autonomia.

Embora a Diretoria de Jornalismo tenha dado importantes passos na definição de uma pauta diária única para todos os veículos da Secom, o conteúdo multimídia (e para multiplataforma) ainda não é, em grande parte, pensado desde a concepção da pauta, de modo que há pouca integração entre os diversos formatos produzidos pela Secom. Da ausência de pauta multimídia, resulta que a Secretaria, em seu conjunto, pode ser caracterizada por uma comunicação multimídia em que ocorre mais remediação do que convergência, nos termos de Canavilhas (2012).

Sobre convergência midiática de conteúdos, o processo implica necessariamente uma linguagem própria com características únicas e diferenciadoras em relação aos restantes meios, e por isso, implica também uma convergência nos processos a montante, aqueles relacionados à produção da notícia: a multimidialidade por acumulação é uma mera remediação e não pode ser vista como convergência de conteúdos (CANAVILHAS, 2012).

Por fim, considerando-se a expectativa de que as mídias especializadas como é o caso das mídias legislativas - complementem o atual espaço informativo (GANDOUR, 2016) e que produção de qualidade refere-se a processos de recepção igualmente de bom nível e respostas socialmente condizentes (ITO, 2019), pode-se 
lançar a hipótese que a Secom poderia acompanhar o "mercado" de jornalismo digital de maneira menos reativa e mais baseada em formatos planejados especificamente para a informação legislativa, apresentando um alinhamento mais forte à missão institucional de contribuir para o exercício da cidadania.

\section{Referências}

BRASIL. Senado Federal. Plano Estratégico 2010-2018: Diretrizes para a Gestão Estratégica da Secretaria Especial de Comunicação Social do Senado Federal. Brasília, DF: Senado Federal, 2010. Disponível em: https://www12.senado.leg.br/noticias/arquivos/planejamento-estrategico-secs2010-2018. Acesso em: 13 abr. 2021.

BRASIL. Senado Federal. [Correspondência]. Secom - Boletim Interno, v. 5, n. 14. Destinatário: servidores da Secretaria de Comunicação do Senado, 16 abril 2021. 1 e-mail.

BARBOSA, S. Jornalismo convergente e continuum multimídia na quinta geração do jornalismo nas redes digitais. In. CANAVILHAS, J. (coord). Notícias e Mobilidade: o jornalismo, na era dos dispositivos móveis. Covilhã: Livros LabCOM, 2013, p. 33-54.

CANAVILHAS, J. Da remediação à convergência: um olhar sobre os media portugueses. Brazilian Journalism Research, Brasília, DF, v. 8, n.1, p. 7-21, 2012. Disponível em: https://bjr.sbpjor.org.br/bjr/article/view/369. Acesso em 30 abr. 2021.

CENTRO REGIONAL DE ESTUDOS PARA O DESENVOLVIMENTO DA SOCIEDADE DA INFORMAÇÃO (CETIC). Pesquisa TIC Domicílios 2019. Sumário Executivo. [S.I.], 2019. Disponível em: https://cetic.br/media/docs/publicacoes/2/20201123115919/resumo_executivo_tic_dom_2019.pdf. Acesso em 18 abr. 2021.

GANDOUR, R. Um novo ecossistema informativo: como a fragmentação digital está moldando a forma pela qual produzimos e consumimos notícias. Austin: Knight Center for Journalism in the Americas, 2016.

GREIFENEDER, R.; JAFFÉ M.; NEWMAN E.; SCHWARZ, N. The psychology of fake news. Accepting, sharing and correting misinformation. London and New York: Routledge, 2021.

ITO, L. L. A (r) evolução da reportagem. Estudo do ciclo da reportagem hipermídia, da produção às respostas sociais. Aveiro: Ria Editoral, 2019.

JENKINS, Henry. Cultura da convergência. ed. aum. e atual. São Paulo: Editora Aleph, 2009.

MARICHAL, J. Facebook Democracy: the architecture of disclosure and the threat to public life. Burlington: Ashgate, 2012.

NUNEZ, S. Dez anos de multimídia: convergência e engajamento público no Portal Senado Notícias. Tese (mestrado). Brasília: Centro de Formação, Treinamento e Aperfeiçoamento (Cefor), Câmara dos Deputados, 2020. 
SCHWINGEL C. Sistemas de produção de conteúdos no ciberjornalismo: a composição e a arquitetura da informação no desenvolvimento de produtos jornalísticos. Tese de Doutorado. Universidade Federal da Bahia. Faculdade de Comunicação. Salvador, 2008.

Artigo recebido em: 20/05/2021

Artigo aceito em: 21/06/2021 